\title{
A and B Theories of Closed Time
}

\section{Phill Dowe}

Australian National University

Department of Philosophy

Canberra

Australia

Phil.Dowe@anu.edu.au

Article info

CDD: 115

Received: 01.03.2017; Accepted: 14.03.2017

DOI: http://dx.doi.org/10.1590/0100-6045.2017.V40N1.PD

Keywords

$\mathrm{A}$ - and B-theories of time

Time travel

Closed time

Special relativity

\begin{abstract}
Closed time is possible in several senses of 'possible'. One might like to know, therefore, whether closed time is possible in the sense that it is compatible with standard metaphysical theories of time. In this paper I am concerned with whether closed time is compatible with $\mathrm{A}$ and/or B theories of time. A common enough view amongst philosophers is that B theories do but A theories do not allow closed time. However, I show that prima-facie neither approach allows closed time, but that with a little work standard versions of both approaches do. This shows that there's no special problem with the notion of eternal return.
\end{abstract}

Manuscrito - Rev. Int. Fil. Campinas, v. 40, n. 1, pp. 183-196, jan.-mar. 2017. 
"That which has been is that which will be."

Ecclesiastes 1:9

\section{Eternal Return}

We start with the Stoics' infamous doctrine of eternal return. According to Nemesius (c.430AD):

The Stoics say that when the planets return to the same position, with respect to inclination and declination, to where each was at the beginning when the cosmos was first established, at specified periods of time they bring about the conflagration and destruction of things. And when again the cosmos returns from the beginning to the same state, and when again the heavenly bodies are similarly disposed, each thing that occurred in the former period will come to pass indistinguishably. ...even to the least details. ..., De Natura Hominis 38, quoted in White 2003 p. 142.

The characterisation of Nemesius doesn't tell us whether the Stoics understood eternal return as closed time or as the exact repetitions of events through time. Let 'eternal recurrence' be where there is exact repetition in linear time, and 'closed time' where time is a closed loop and the world returns to the numerically same state. According to Simplicius the Stoics were well aware of the difference: "[they] reasonably ask whether the I now and the I then are one in number, or whether I am fragmented by the ordering of cosmic cycles one to the next." (quoted in White 2003 p. 142). Prominent contemporary commentators such as MJ White have argued that for the Stoics eternal return was closed time, the main reason being that they take it as uncontroversial that the Stoics believed in the identity of indiscernibles, which means that there cannot be eternal recurrence, and the only way to have eternal return is in closed time.

Subsequent philosophers did not buy closed time. Aristotle argued that one and the same now cannot be both the beginning and the end of the same period of time, because opposites "cannot hold simultaneously in respect of the same thing" (Aristotle Physics IV. 12: 222 4-6, quoted in

Manuscrito - Rev. Int. Fil. Campinas, v. 40, n. 1, pp. 183-196, jan.-mar. 2017. 
Coope 2005 p. 80.) This is not a troubling argument, because as Coope points out, in closed time the beginning and the end of a time period might not be opposites. Even more influentially, Augustine argued:

... if, for example, the philosopher Plato, having taught in the school at Athens which is called the Academy, so, numberless ages before, at long but certain intervals, this same Plato and the same school, and the same disciples existed, and so also are to be repeated during the countless cycles that are yet to be,- - far be it, I say, from us to believe this. For once Christ died for our sins; and, rising from the dead, He dieth no more. "Death hath no more dominion over Him" (The City of God; Chapter 13.-Of the Revolution of the Ages, Which Some Philosophers Believe Will Bring All Things Round Again, After a Certain Fixed Cycle, to the Same Order and Form)

Clearly Augustine took the Stoics to be proposing eternal recurrence, because the argument doesn't work for closed time! But a more general and deeply influential reason that Augustine has, although he doesn't say it in as many words, is this: history is linear, the outworking of a purpose, from Creation to Judgement Day in contradistinction to Zoroastrianism where one Epoch ruled by good is followed by the Epoch ruled by evil, repeat. But this reason and the first one should only lead Augustine to say contingently time is linear. He could have said, perhaps depending on your interpretation of Augustine's views about Divine Freedom: God is outside of time, time is part of the created order. God could have created closed time, but he didn't because it didn't suit his purposes. This is not a metaphysical problem in the sense in use in this paper.

It's often claimed that everyone was a presentist until the19th century. Bigelow (2001) says until then we lacked the conceptual resources to be eternalists (I think there are counterexamples), but if the Stoics were presentists, then it begs the question: how might they reconcile presentism with closed time? It would certainly diminish our assessment of the Stoics if their apparent theory of time was inconsistent with eternal return.

Manuscrito - Rev. Int. Fil. Campinas, v. 40, n. 1, pp. 183-196, jan.-mar. 2017. 


\section{Closed Time-like Curves}

In 1949 Gödel offered a new solution to Einstein's field equations in the general theory of relativity (1949a). The solution in question defines a world (a 'Gödel world') which is a large slowly rotating disc, and which famously contains closed time-like curves. He further argued (1949b) that that for time to be objective it must be definable in all physically possible worlds, and the Gödel world is such that an objective lapse of time is not definable, therefore time is ideal, including for our own world. By 'an objective lapse of time' Gödel means "that reality consists in an infinity of layers of "now" which come into existence successively" (1949b p. 558). This is clarified in footnote 4 where Gödel refers to "...the idea of an objective lapse (whose essence is that only the present really exists)..." (1949b p. 558 n. 4). In other worlds, Gödel's objective lapse of time is essentially presentism, the view that only the present exists in a tenseless sense of 'exists'.

Gödel offers at least two arguments that no objective lapse is definable in a Gödel world. The first argument, well known, is that there is no objective lapse "because the local times of the special observers ... cannot be fitted into one world time." (1949 p. 560) Of course, as for any world, it is possible to partition the Gödel world into mutually exclusive jointly exhaustive hypersurfaces, but the problem in a Gödel world is that for any way of doing that, no consistent way to order those hypersurfaces into a time order can be found. This first argument against objective lapse in a Gödel world is sound, and indeed works against any conception of time committed to universal now slices.

Gödel's second argument that no objective lapse is definable in a Gödel world is less well known. Gödel says "...that for every possible definition of a world time one could travel into regions of the universe which are passed [sic] according to that definition. This again shows that to assume an objective lapse of time would lose every justification in these worlds." (1949b p. 561). Unless this is taken to be a re-statement of Gödel's first argument, it would seem to be fallacious. To see this, note that the condition 'for a given world $W$ with a given global time function it is possible to traverse a time-like curve from a point $p$ and reach a point in the past of $p$ in $W$ is met in any cyclical world, for example a Newtonian

Manuscrito - Rev. Int. Fil. Campinas, v. 40, n. 1, pp. 183-196, jan.-mar. 2017. 
space-time rolled up like a cylinder in the $t$ dimension. But in such a world a global cyclic order of hypersurfaces is definable:

Given a set $X$ and a ternary relation $a$ on $X$, we consider the following possible properties of $a$ :

Cyclicity: for all $\mathrm{x}, \mathrm{y}, \mathrm{z} \in \mathrm{X}, \alpha(\mathrm{x}, \mathrm{y}, \mathrm{z})$ implies $\alpha(\mathrm{y}, \mathrm{z}, \mathrm{x})$, Anti-reflexivity: for all $\mathrm{x}, \mathrm{y} \in \mathrm{X}$, not $\alpha(\mathrm{x}, \mathrm{x}, \mathrm{y})$,

Transitivity: for all $\mathrm{x}, \mathrm{y}, \mathrm{z}, \mathrm{t} \in \mathrm{X}, \alpha(\mathrm{x}, \mathrm{y}, \mathrm{z})$ and $\alpha(\mathrm{z}, \mathrm{t}, \mathrm{x})$ imply $\alpha(\mathrm{y}$, $z, t)$

... Given a set $\mathrm{X}$, a cyclic order on $\mathrm{X}$ is a ternary relation on $\mathrm{X}$ which is cyclic, anti-reflexive and transitive. (Ille and Ruet 2008 p. 120).

The ternary relation $a[a, b, c]$, can be intuitively understood as "after $a$, one reaches $b$ before $c$ ", which for cyclic time provides an order sufficient to answer Gödel's second argument (although it is symmetric - see below).

Thus, in such a cyclical world, a satisfactory notion of objective lapse wherein one takes the global simultaneity slices to come in and out of existence successively - is not disproved. This, of course, does not mean that there can be "objective lapse" in a Gödel world, but it does mean that Gödel's second argument is fallacious. This has implications for a view around today that presentism is incompatible with closed timelike curves, such as that evidenced in the comments of Dean Zimmerman, who in response to the problems raised by Gödel says "I should think the Atheorist may, with a relatively clear conscience, reject non-foliable models as not genuinely possible ways for time to be." (2011 p. 38). But a Newtonian space-time rolled up like a cylinder is non-foliable ( $=$ not divisible into spacelike slices such that every time-like extendable line crosses each slice once and only once) but not subject to either of Gödel's arguments.

\section{$A$ and $B$ Theories}

For A-theories time is the change from future to present to past in events so ordered. For B-theories time is the ordering of events by Brelations such as 'earlier than'. The terminology is of course adapted from

Manuscrito - Rev. Int. Fil. Campinas, v. 40, n. 1, pp. 183-196, jan.-mar. 2017. 
McTaggart (1908). It is odd to use the term 'series' because in mathematics a series is a sum of the terms in a sequence. McTaggart means that the events are ordered. 'Order' is ambiguous too. Sometimes it means a series with a one-way direction, such as in the mathematical definition of an ordered set, the sense McTaggart intends; and sometimes it means something symmetric, such as in a prominent 20 th century version of the causal theory of time which gets 'order' from the undirected betweeness relation, and then adds on top of that order a direction by appealing to some time-asymmetric physical process such as entropy decrease.

The A/B theory distinction maps onto accounts of what exists. The most common A theories are presentism - only the present exists in a tenseless sense of 'exists', and the growing block - only the present and past exists. The change from from future to present to past is becoming. The B-theory corresponds to eternalism - the past, future and present all exists in a tenseless sense of 'exists' - according to which there is no becoming.

A common enough view amongst philosophers is that $\mathrm{B}$ theories do but A theories do not allow closed time:

After the empirical success of general relativity, [the A-theorist owes us] an error theory over the empirical success of a scientific theory of time which is highly unlike any conceivable A-series (Richmond 2003, p. 307.)

... a structure of the sort [containing closed time-like curves] could only exist in a block universe... (Dainton 2001 p. 130.)

It may be that there are other sorts of stories which can be correctly regarded as time-travel stories and which are not compatible with presentism....We have in mind those time-travel stories that make essential reference to closed loops ...in space-time. Nothing we say will suggest that these stories are compatible with presentism. (Keller and Nelson 2001 p. 334.)

My aim in challenging this sort of attitude is fairly modest- I'm restricting myself to closed time.

But there are prima facie problems for both $\mathrm{A}$ and $\mathrm{B}$ theories, and solutions available to the B theory are available to the A theory also. The

Manuscrito - Rev. Int. Fil. Campinas, v. 40, n. 1, pp. 183-196, jan.-mar. 2017. 
prima facie problem is that for neither A nor B theories will the 'time-like' dimension in any alleged case of closed time actually count as time. For the A-theory, at any point on a closed curve we take to be time, every point on that curve will be both future and past. Events do not stop being future when they become present or past. And they don't become past since they are already past (Dowe 2009). So there is no change in events from future to present to past, so there is no time. For the B theorist, either every point on a series of points we call a closed time-like curve will be earlier than, and later than, every other point on that curve; or the points on the curve are not related as 'earlier than' at all. Either way, the events are not ordered by the 'earlier than' relation, and so this will not count as time.

\section{Back To The Seventies}

In the 1970's - eg van Fraassen (1970) and Newton-Smith (1980) closed time figures very prominently. This century closed time is rarely mentioned, rather it seems to be subsumed under the category of 'worlds containing closed time-like curves' without much care. So comments about the problems that A-theories such as presentism face with say Gödel worlds are made which seem to be intended to apply to closed time; when often they don't.

According to van Fraassen (1970) we can get an order in closed time from the separation relation:

Separation (Vailati Axioms). For points $a, b, c, d$ :

1. $S(a, c / b, d)$ iff $S(b, d / a, c)$

2. $S(a, c / b, d)$ iff $S(c, a / d, b)$

3. If $S(a, c / b, d)$ then not $S(a, b / c, d)$

4. If $S(a, c / b, d)$ and $S(a, b / c, e)$ then $S(a, b / d, e)$

5. If $a, b, c, d$ are non-simultaneous points, then $a$ is separated from one of the others by the remaining two. (van Fraassen 1970 p. 69.) 
Intuitively $S$ (separation) says that $a, c$ separate $b, d$ (i.e. $S(a, c / b, d)$ ) if there's no way to go from $b$ to $d$ without going through $a$ or $c$. Axiom 5 . rules out a figure eight. For four non-simultaneous points in closed time there will be two points which separate the other two (symmetrically as per axiom 1). What does this achieve? Well, the hope would be that this is a B-theoretic surrogate for 'earlier than'. It's not. It's obviously a symmetric order such that $a-b-c-d$ is not distinguished from $d-c-b-a$. There's no direction to time. The hope would be, as mentioned above, that if we're concerned with the causal theory of time, as van Fraassen is, we could add something like the entropy gradient to provide the direction. Unfortunately it's not clear how this can work. For closed time there cannot be a global entropy gradient. Suppose we 'start' with low entropy at point $a$, followed by a period of entropy increase, then we would need a corresponding period of entropy decrease for consistency, i.e to arrive at the stipulated entropy value at $a$.

Much the same picture emerges for the A-theory. According to Newton-Smith (1980) we can get an A-theoretic order from the notion of tensed separation:

Tensed Separation. For points $p, q, r$. $\psi(p, q, r)$ at $t_{0}$ iff

1. $q, r$ are sometimes true, at $t_{q}$ and $t_{r}$ respectively say, and

2. $p$ will be true at a $t_{p}$, such that $S\left(t_{0}, t_{p} / t_{q}, t_{r}\right)$.

$\varphi(p, q, r)$ at $t_{0}$ iff

1. $q, r$ are sometimes true, at $t_{q}$ and $t_{r}$ respectively say, and

2. $p$ was true at $t_{p}$, such that

3. $S\left(t_{0}, t_{p} / t_{q}, t_{r}\right)$. (Newton-Smith 1980 p. 62, edited).

$\psi$ is a stand-in for the future tense operator, $\varphi$ for the past tense operator and $S$ is the Vailati separation. "This gives an order in terms of tense", says Newton-Smith. Leaving aside the fact that it appeals to B theoretic separation, not surprisingly it also only provides a symmetric ordering with no direction - there's no surrogate for the distinction between past and future. $\psi(p, q, r)$ is equivalent to $\psi(p, r, q)$, and moreover equivalent to $\varphi(p, q, r)$. So tensed separation doesn't give you an A-series.

Manuscrito - Rev. Int. Fil. Campinas, v. 40, n. 1, pp. 183-196, jan.-mar. 2017. 
So, leaving the seventies, let's see if we can do any better.

\section{Local Time}

We start with some rough ideas of A and B theoretic local time. 1. For the B-series, let $L(p, q)$, ' $p$ locally before $q$ ' be an asymmetric irreflexive relation. Then 'earlier than' is the ancestral of $L$, and is non-symmetric, non-reflexive, transitive. 2. For the A-series the basic designations is locally future', 'is locally past' are exclusive. This is not transitive, so we need assumptions about the possible structures. One immediate problem is that local is a spatiotemporal concept, and for the kind of B-theory which wants to construct time out of the earlier than relation (or its surrogate), whether it takes time or causation as primitive, it looks circular and arbitrary - e.g. how to deal with plank scale ctc's of spacetime foam (we won't address this particular problem as we are only dealing with closed time).

Putnam once said "I do not believe that there are any longer any philosophical problems about Time; there is only the physical problem of determining the exact physical geometry of the four- dimensional continuum that we inhabit" (Putnam 1967, p. 246). You can take this with a pinch of salt, yet still see some truth in it. In fact, I believe we can divide B-theorists into two camps according to how they sit with regard to the spacetime manifold. Some want the spacetime defined, then go on to see if there are any interesting questions about time; others mostly ignore the spacetime and talk primarily about time in terms of the primitive earlier than relation or the causal relation. The former say "define the spacetime or I don't know what you're talking about", and the latter say, "no, this is metaphysics". The former approach makes our question relatively trivial.

We start by defining a spacetime eg a Minkowski spacetime. We define a manifold, and then a metric. We get a lightcone structure at every point, and a direction (if orientable) at every point. We can define relations on the spacetime, eg, trivially, earlier/later or past/future. However, if we have a closed-time spacetime, eg a cylindrical Minkowski spacetime rolled up in the temporal dimension, we can't just define before/after or past/future, as we've seen, at least not in the usual senses.

Manuscrito - Rev. Int. Fil. Campinas, v. 40, n. 1, pp. 183-196, jan.-mar. 2017. 
The past/future lightcones at any point all pick out the same region, the entire spacetime. But since there's an arrow at every point pointing futureward, we can order events in a B-series with a direction - if we can call it a B-series since it's not ordered by earlier than. This is not a B-theory on my definition. At this point Putnam might have a point- who cares, you've said everything interesting. Nevertheless, let me try for a surrogate.

1. Closed Time B-Surrogate. Start by defining a closed spacetime as we've just indicated, helping ourselves to a metric. Then we can define 'temporal distance' $t_{f}(a, b)$ in the forward direction, and the past direction $t_{p}(a, b)$. Then we can define a notion of local time:

Proximally before: $\mathrm{a}$ is proximally before $\mathrm{b}$ iff

1. $\mathrm{b}$ can be reached from $\mathrm{a}$ in the forward direction at a non-zero temporal distance $t_{f}(a, b)$ and

2. if $\mathrm{b}$ can be reached from $\mathrm{a}$ in the backward direction at a nonzero temporal distance $t_{p}(a, b)$, then $t_{f}(a, b)<t_{p}(a, b)$.

'Proximally before' is a surrogate of 'earlier than'. It's irreflexive and nontransitive. And most significantly, it's asymmetric. So it orders events in a B-series.

2. Local Presentism in Closed Time. It has often been argued that Atheories are incompatible with relativity: A-theories entail an absolute simultaneity, but in Special Relativity simultaneity is frame dependent (Putnam 1967) and in General Relativity the choice of a foliatation (a division into exclusive time-slices) is arbitrary. One response is to attempt to give a relativistic A-theory. According to Stein(1968) becoming can be defined in terms of space-time points: 'real for point $p$ ' holds for $p$ and all points in $p$ 's backward lightcone. All else is merely possible for $p$. On this view becoming is understood as the successive division of space-time along a worldline into what is real and what is merely possible. But 'successive' is 'detensed' - just a way of talking about the array of tenseless relations. This is a static growing block A-theory and is usually called 'possibilism'. (The reader will have to excuse the infelicitous terminology

Manuscrito - Rev. Int. Fil. Campinas, v. 40, n. 1, pp. 183-196, jan.-mar. 2017. 
“static growing block"). I call it 'local presentism'. It's notable not only for it's lack of a universal now-'now' is a 'here-now'- but also for the fact that it makes 'is real' a relation. Stein is not concerned that his account does not cohere with common sense, but Savitt, noting the lack of any intersubjective present in Stein's version, instead defines 'real and present for space-time points $p, q$ ' as the region containing $p$, an earlier event $q$, and the overlap between $p$ 's backward and $q$ 's forward light cones, where the distance between $q$ and $p$ is the measure of a minimum time of conscious experience (Savitt 2005, fn 17, p. 421, see also Arthur 2006). Thus we have the local presentism account:

Local Presentism: 'Present for space-time point p' is defined as the region containing $\mathrm{p}$, an earlier event $\mathrm{q}$, and the overlap of $\mathrm{p}$ 's backward with q's forward light cones, where the distance between $\mathrm{q}$ and $\mathrm{p}$ is the measure of a minimum time of conscious experience. (c.f. Savitt 2005; Arthur 2006).

According to Savitt this account works in closed time. It doesn't. The problem is that in in closed time the present for any point becomes all of spacetime. Here's where the 'proximally before' relation can do some work. Consider the overlap of the proximally future lightcone and the proximally past light cone. Then:

'Present for spacetime points $p, q$ ' is the overlap between the sets $P$ and $Q$, where $P$ is the set: $p$ and all points $x$ such that

(i) $x$ is in $p$ 's backward light cone and

(ii) if $p$ and $x$ both lie on any closed timelike curve, then for all closed timelike curves containing both $p$ and $x, x$ is closer to $p$ in the past direction than in the future direction as measured by the proper time along that curve;

and $Q$ is the set: $q$ and all $y$ such that

(i) $y$ is in $q$ 's forward light cone and

(ii) if $q$ and $y$ both lie on any closed timelike curve, then for all closed timelike curves containing both $q$ and $y, y$ is closer to $q$ in the future direction than in the past direction as measured by the proper time along that curve. 
So we have a version of local presentism which does not have the implication that in closed time the intersubjective now is all of spacetime.

3. Closed Time A-Surrogate. The A-theorist can make essentially the same move as the B-theory. The entire set of currently obtaining paired metrically tensed facts gives a metric, and fixes that time is closed. It has to be consistent, of course:

We have closed time only if it is the case that for any presently obtaining fact, such as

it will be the case by 30 years that $a$, it will be the case by 10 years that $b$, it was the case by 10 years that $c$, it was the case by 30 years that $d$ will be paired with an appropriate alternative tensing of the same proposition, viz

it was the case by $T-30$ years that $d$, it was the case by $T-10$ years that $c$, it will be the case by $T-10$ years that $b$, it will be the case by $T-30$ years that $a$ where $T$ is the period of closed time, and where these tensed propositions are irreducibly metric.

Typically, a presentist appeals to nonmetric tense to get an order and a direction, and to metric tense to get a metric (Bigelow 1996). I don't prove that that can't work, but I assert it. However, if we start with metric tense we can then make use of a surrogate of past/future:

Proximal Future: For any events $a$ and $b$ : when $a$ present $b$ is 'proximally future' iff

(1) $b$ is future and

(2) if $b$ is past but not present, then $b$ is closer in the futureward direction than it is in the pastward direction. Similarly for proximally past.

Manuscrito - Rev. Int. Fil. Campinas, v. 40, n. 1, pp. 183-196, jan.-mar. 2017. 
This simplifies to future/past in linear time. For closed time it can be used as a straight surrogate for past and future in ordering A-series and gives us a language to say things like

'becoming consists in the proximally future becoming present then becoming proximally past', something we can't say in terms of straight future/past denominations.

So it's not clear that there is any advantage in being a B-theorist when it comes to closed time. Both A and B theories have prima facie problems in closed time, and both are amenable to 'local' surrogates.

\section{References}

Augustine [426] The City of God. Translation by Marcus Dods. New York: The Modern Library, Random House, 1950.

ARTHuR, R. "Minkowski Spacetime and the Dimensions of the Present" in The Ontology of Spacetime, Vol. 1, ed. Dieks, D. (ed.), 129-155. Amsterdam: Elsevier, 2006.

Bigelow, J. "Presentism and Properties" Philosophical Perspectives 10: 3552, 1996.

Bigelow, J. (2001) "Time Travel Fiction", in Reality and Humean Supervenience: Essays on the Philosophy of David Lewis, ed. G. Preyer and F. Siebelt, 58-91. Lanham: Rowman \& Littlefield, 2001.

Coope, U. "Time for Aristotle: Physics IV.10-14". Oxford: Oxford University Press, 2005.

Dainton, B. Time and Space. McGill: Queens University Press, 2001.

Dowe, P. "Every Now and Then: A-theory and Loops in Time" Journal of Philosopby 106:641-665, 2009.

GÖDEL, K. "An Example of a New Type of Cosmological Solution to Einstein's Field Equations of Gravitation" Reviews of Modern Pbysics 21:447-450, 1949a.

Manuscrito - Rev. Int. Fil. Campinas, v. 40, n. 1, pp. 183-196, jan.-mar. 2017. 
"A Remark About the Relationship Between Relativity Theory and Idealistic Philosophy" in Albert Einstein: Philosopher-Scientist, ed. P. Schilpp, 557-562. La Salle, IL: Open Court, 1949b.

Ille, P. and RUET, P. "Cyclic Extensions of Order Varieties" Electronic Notes in Theoretical Computer Science 212: 119-132, 2008.

Keller, S. and Nelson, M. "Presentists Should Believe in Time Travel" Australasian Journal of Philosophy 79:333-345, 2001.

MCTAGgART, J. “The Unreality of Time” Mind 18: 457-475, 1908.

NewTON-Smith, W. The Structure of Time. London: Routledge, 1980.

Putnam, H. "Time and Physical Geometry" Journal of Philosophy 64: 240_ 247, 1967.

Richmond, A. "Review: Time Travel" Philosophical Books 44: 297-309, 2003.

Van Fraassen, B. An Introduction to the Philosophy of Time and Space. New York: Random Press, 1970.

SAVITT, S. "Time Travel and Becoming” The Monist 88: 413-22, 2005.

STEIN, H. "On Einstein-Minkowski Space-Time” Journal of Philosophy 65:523, 1968.

White, M. "Stoic Natural Philosophy" in The Cambridge Companion to the Stoics, ed. Inwood, B., 124-152. Cambridge: Cambridge University Press, 2003.

Zimmerman, D. "Presentism and the Space-Time Manifold" in The Oxford Handbook of Philosophy of Time, ed. C. Callender, 163-244. Oxford: Oxford University Press, 2011.

Manuscrito - Rev. Int. Fil. Campinas, v. 40, n. 1, pp. 183-196, jan.-mar. 2017. 